\title{
Validation of an Instrument Applied in Public Institutions of Ecuador to Know the Use of Intelligent Systems
}

\author{
https://doi.org/10.3991/ijoe.v15i12.11007 \\ Washington Garcia Quilachamin $\left.{ }^{(}\right)$ \\ Universidad Nacional Mayor San Marcos, Lima, Perú \\ Universidad Laica Eloy Alfaro de Manabí, Manta, Ecuador \\ profegarcia501@gmail.com \\ Luzmila Pro Concepción \\ Universidad Nacional Mayor San Marcos, Lima, Perú \\ Evelyn Santana Mantuano, Richard José Salazar \\ Universidad Laica Eloy Alfaro de Manabi, Manta, Ecuador
}

\begin{abstract}
The development of technologies associated with energy efficiency and use in lighting systems, arise as problems in the application of smart devices in different places such as: houses, buildings, industries, companies and public and private institutions. The objective of the study was to validate the instrument and the information obtained on the use of intelligent devices such as automatic control in a lighting system and its improvement in energy efficiency in the public sector. As a research methodology, a field study was conducted, based on a survey applied to 231 employees (bosses and workers) who work in 17 public institutions located in 6 cantons of the province of Manabí, Republic of Ecuador. To validate this instrument, an exploratory and confirmatory factorial analysis of the data obtained was carried out. As a result of the principal component analysis, a factor transformation matrix (0.870) was obtained and the reliability analysis was obtained $(0.880)$ in relation to the reagents that describe three dimensions established in knowledge, application and technology management. It is concluded that the factor analysis applied through the KMO test, Bartlett's sphericity and Cronbach's alpha coefficient, with a correlation range $\geq 0.5$ between reactants was feasible, which allows to certify the reliability and validity applied in this instrument.
\end{abstract}

Keywords-Technologies, smart devices, lighting systems, electric systems, energy efficiency.

\section{Introduction}

Every day new technological advances are generated, which will be used in our environment, as is the case of smart technologies, which facilitate the automation of the 
sites where they are implemented, considering the authors [1], who say that the development of telecommunications and information technologies has promoted smart networks that are the electrical networks that can intelligently integrate the behavior and actions of all the actors related to they (those that generate electricity, those who consume and those who perform the actions of actions) in order to provide a safe, economical and sustainable electricity supply.

Therefore, taking into account the continuous development of technologies and the different combinations of them in homes, offices and certain areas, the developed method must be generic to verify the quality of the technology, being the application of a device that allows connectivity with lighting systems and use several scenarios that allow energy efficiency in electricity, [2].

In accordance with the organic law of the electric power public service in Ecuador, in 2008 the restructuring of the electric sector began, which led to considerable changes, such as: the fixing of the single tariff, the concept of marginal costs for the calculation of generation costs, the participation of the state in the investment for the expansion in distribution and transmission costs and the cessation of obligations by electricity companies for electricity transactions.

The sophistication and age of electrical networks in the 21 st century vary significantly within a country. According to [3], they consider that there is a constant increase in annual energy, due to the consumption and use of technological, electrical and household appliances; which are a consequence of population growth and increased economic activity.

The consumption of energy in the TIC industry, the authors [4] consider the use of computers, equipment and electrical devices, excluding servers. Therefore, to reduce this growing trend, many mechanisms have been stimulated, such as the use of sensors in home accessories and in specific areas of companies and institutions. These processes represent a solution to save energy and improve energy efficiency.

It's considered [5], who mentions that society in different regions of our planet, has become aware of the energy problem that is living, that is why it has developed different programs around energy efficiency, with the aim of taking care of resources that we still have and are present in our environment.

Taking into account the appearance of problems in automation due to the adoption of smart devices in areas, organizations, homes where they are implemented, as stated by the author [6] and that no expense is spared, because a system Conventional luminaire lighting is manual; and don't always turn off after use, generates unnecessary consumption of electrical energy and shortens the time of use of lighting systems.

For what is considered as the objective of this study, to analyze the situation in the application of intelligent devices such as the automatic control of a lighting system and its improvement in energy efficiency in the public sector, which was developed through a study of field using a questionnaire as a tool to obtain information.

This work develops with an introduction to intelligent systems as a technology adopted in lighting, its consumption in energy efficiency systems. Thus, it also describes a methodology that includes the way how it has developed for this study, the participants involved, instrument, statistical analysis, exploratory application. The results found through factor analysis are shown in statistical tables, which are analyzed considering the most 
relevant data of the present study and finally describes the conclusions reached in this research.

\section{$2 \quad$ Methodology}

\subsection{Participants}

To analyze the limited application of smart devices and to have information that could serve as the basis for proposing this instrument, this research was based on a field study carried out in 17 institutions in 6 cantons of the province of Manabi, completing a total of 231 surveys, made to officials of these institutions.

The data collection was directed to employees (heads and workers) who work in technical areas, maintenance, logistics and administration of each institution, in which the survey was developed. This study is contemplated at determining which technologies are related to the application of intelligent devices such as the automatic control of the lighting system and the improvement of energy efficiency in public institutions in the province of Manabí.

\subsection{Instrument}

The questionnaire of 35 items was applied at the end of each of these units or thematic block and was developed in two parts, the first of 9 items refers to the personal, academic and employment data of the respondent. The second consists of 26 items associated with energy efficiency in lighting systems, with the objective proposed in this study and established in the institutions involved to determine if this type of technology is used; likewise, this second part was based on three dimensions: knowledge, application and management.

In all cases, the employees of each public institution answered the questionnaire anonymously using an electronic reading sheet designed for the type of response required. The reading of the sheets and the generation of the data files were carried out by the authors. On the basis of the information provided by the reading of the response sheets, the corresponding databases were prepared for the analysis, both in Excel and SPSS format.

\subsection{Statistical analysis}

In this study, factor analysis (FA) is used, which is a statistical model that represents the relationships between a set of variables. For what is considered in this investigation the author [7], who states that these relationships can be explained from a series of unobservable (latent) factors called factors, the number of factors being substantially less than that of the variables.

For this, the exploratory factorial analysis (AFE) was considered as a technique and the dimensions and number of established reagents were validated using the sta- 
tistical software SPSS (Statistical package for social science), as declared by the authors [8], which allowed the results to be reliable.

According to [9], through the AFE, the variability of the scores of a set of variables is explained by a smaller number of dimensions or factors. In this way, for example, a large number of test items can be reduced to a small number of factors or dimensions (verbal aptitude, extraversion, for example) that confer a theoretical significance to the measurement. Each of these factors groups the interecorrelated items that, at the same time, are relatively independent of the other sets (factors) of items.

The author is considered [10], who mentions that in order to determine the construct validity of the questionnaire, complementary factorial tests are developed. Therefore, a Principal Components Analysis (CP) is applied, which covers the objective of demonstrating the univocal structure presented by the entire questionnaire aimed at the measurement of a latent trait. In our research, we consider the technologies applied to lighting systems with energy efficiency criteria, so it is expressed through a certain linear combination of the variables contained in the questionnaire.

Considering the dimensions of the established reagents, a correlation coefficient> 0.5 was obtained as a feasible result in relation to the exploratory factor analysis of the data obtained in the survey that was applied in 17 public institutions of 6 cantons of the Province of Manabí.

\subsection{Application of the instrument}

To demonstrate the reliability and validity of the questions proposed in the survey, we proceed to develop the factor analysis tests as it manifests [7]. These tests were performed in the statistical software SPSS (Statistical package for the social sciences) [8]; through which a principal components analysis is applied to reduce the number of variables and, therefore, limit the variables that are more related, since the greater the variability of the data, the greater the information obtained, according to [11] and what allows us to validate the data generated as they consider it [12].

Prior to the analysis of main components, statistical tests were performed on KMO (Kaiser-Meyer-Olkin) and Bartlett's sphericity, considering the author [13], which relates the correlation coefficients and evaluates the applicability of the factorial analysis of the variables in question, respectively; that the closer they are to 1, the values obtained in the KMO test, means that the analysis is feasible; In the developed study, values greater than 0.5 were taken; that is, while the data obtained are in the range of $\geq 0.5$, it indicates that there is a high intercorrelation between the variables and factor analysis would be feasible, as considered [14].

\subsection{Reliability validation}

Taking into account the authors [15], the factorial analysis of the reliability performed, using the SPSS and by calculating the Cronbach alpha coefficient, the reliability of the internal consistency of the instrument was determined. The reagents (on the Likert scale) measure the same construct and are highly correlated. According to 
the criteria of the authors [16], [17], they mention that the closer the value of Cron Bach's alpha to 1 is, the greater the internal consistency of the elements analyzed.

\subsection{Factorial analysis}

With respect to the factorial analysis carried out in the second part of the survey that was applied in public institutions in 6 cantons of the Province of Manabí, we noticed that in order to arrive at a definitive result and establish the questions that are related to each other, in relation to the Energy efficiency in lighting systems was developed in four phases: the first, in which 10 reagents were extracted that had a correlation coefficient below 0.5 , as indicated [18]; in the second phase, 5 reagents were extracted, since the result of the correlation was not within the established range; In the third phase, after having eliminated 10 and 5 reagents respectively (of the 26 considered in the second part of the survey), we proceed to exclude 2 of these variables and develop the fourth phase in which it is shown that the 9 items are correlate each other, with a correlation coefficient $>0.5$, which determines that factor analysis is feasible as considered [9].

\section{Results}

The results show that there is a relationship between the knowledge and devices used to control lighting systems, considering that the percentage of responses was in a balance between high and regular knowledge. Regarding the application of these innovations in the institutions involved, an unfavorable result was achieved, according to the data obtained in the survey conducted, it was found that more than $50 \%$ of the respondents answered that in the area in which they work they do not count with devices associated with lighting systems. In addition, in relation to the management, there was predisposition on the part of the people surveyed, since they responded favorably to consider being trained in the use of methods and technologies with criteria in energy efficiency applied to lighting systems, with this knowledge applied in your area and place of work as well as in your homes.

\subsection{Results and analysis of the first phase}

In phase 1 , the 26 elements of the second part of the survey are entered in the SPSS program, to perform the reduction of the dimensions and the factorial analysis, within which the KMO and Bartlett sphericity tests are applied. The correlation rank $\geq 0.5$ between the reagents was considered as a reference, after that, the analysis of the main components was applied, showing the correlation that exists between the variables entered. The obtained results allow to demonstrate that the analysis is feasible, since, within the KMO tests, it is demonstrated that the study is within the established range and in Bartlett it is determined that the correlations between the variables are different from zero, that is, they say that there is a correlation between them. (0.854). See Table 1. 
Table 1. KMO score and Bartlett test

\begin{tabular}{|l|l|c|}
\hline Sampling adaptation measure of Kaiser-Meyer-Olkin. &, 854 \\
\hline \multirow{3}{*}{ Bartlett's sphericity test } & Chi-cuadrado aproximado & 2552,414 \\
\cline { 2 - 3 } & Gl & 325 \\
\cline { 2 - 3 } & Sig. &, 000 \\
\hline
\end{tabular}

In the table of the matrix of rotated components, it is obtained that all the variables have a correlation with each other, but taking into account that in this study a range of $\geq 0.5$ was considered, for this reason, minor correlations to such magnitude were extracted. of the analysis, to achieve a greater variability of the data obtaining a value that approaches 1 . In this first phase, it was obtained that, of the 26 items analyzed, 10 of them resulted with a lower correlation with the established value, so that a second phase is established, within which the reagents to be extracted will not be included.

In Table 2 the reagents that are eliminated are highlighted in bold and underlined.

To conclude this first phase, it is observed in Table 3 , that in the transformation matrix of the components, if there is a relationship between each of the factors when using the rotation method: Varimax normalization with Kaiser.

Table 2. Component transformation matrix

\begin{tabular}{|c|c|c|c|c|c|c|}
\hline Components & $\mathbf{1}$ & $\mathbf{2}$ & $\mathbf{3}$ & $\mathbf{4}$ & $\mathbf{5}$ & $\mathbf{6}$ \\
\hline 1 &, 789 &, 448 &, 176 &, 259 &, 277 &, 038 \\
\hline 2 &,- 532 &, 722 &, 420 &, 122 &,- 041 &, 049 \\
\hline 3 &, 209 &,- 304 &, 736 &,- 085 &,- 521 &, 211 \\
\hline 4 &,- 176 &,- 357 &, 173 &, 869 &, 177 &,- 158 \\
\hline 5 &,- 140 &,- 219 &, 264 &,- 213 &, 707 &, 563 \\
\hline 6 &, 004 &, 101 &,- 388 &, 332 &,- 344 &, 781 \\
\hline
\end{tabular}

\subsection{Results and analysis of the second phase}

Taking into account the analysis of the first phase, in which 10 variables were not considered, the second procedure was performed, in which a correlation lower than the established one was obtained and in which the maximum probability is considered as analysis. Remaining reagents that are not within the correlation range are also discarded and the sedimentation graph option is activated to determine how many factors are retained after the first phase. 
Table 3. Matrix of rotated components

\begin{tabular}{|c|c|c|c|c|c|c|}
\hline \multirow{2}{*}{ Reagents } & \multicolumn{6}{|c|}{ Components } \\
\hline & 1 & 2 & 3 & 4 & 5 & 6 \\
\hline Do you know the types of sensors used in lighting? &, 834 &, 050 & 059 & 047 & \begin{tabular}{|l|}
, 145 \\
\end{tabular} &, 004 \\
\hline $\begin{array}{l}\text { Do you know about the latest technological advances in } \\
\text { energy efficiency? }\end{array}$ &, 823 &, 148 &, 038 &,- 051 &, 037 &,- 002 \\
\hline Do you know about sensors? &, 809 &, 042 & ,036 & ,109 & \begin{tabular}{|c|}
, 068 \\
\end{tabular} &,- 118 \\
\hline Know the benefits of renewable energy? &, 807 & ,065 &,- 187 &,- 033 & \begin{tabular}{|l|}
, 120 \\
\end{tabular} & ,023 \\
\hline Do you have knowledge about energy efficiency? &, 744 &, 170 &,- 024 & ,067 &,- 057 & 131 \\
\hline $\begin{array}{l}\text { Do you know about light devices connected to a wireless } \\
\text { network? }\end{array}$ &, 724 &, 131 &, 162 & ,193 &, 036 &,- 015 \\
\hline Do you have knowledge about traditional energies? & ,711 & ,066 &,- 069 &, 083 & 254 & 131 \\
\hline $\begin{array}{l}\text { You know the cameras of recognition of people with sensors } \\
\text { for lighting fixtures }\end{array}$ &, 651 &, 010 & ,248 &, 250 &, 214 &,- 023 \\
\hline $\begin{array}{l}\text { To what extent is technological management applied to energy } \\
\text { efficiency in involved institutions? }\end{array}$ &, 028 &, 807 &, 128 &, 086 &, 005 &, 028 \\
\hline $\begin{array}{l}\text { What are the levels of application based on the recognition of } \\
\text { people for the management of energy efficiency in involved } \\
\text { institutions? }\end{array}$ &, 120 & ,781 &, 153 &, 006 &, 092 & 099 \\
\hline $\begin{array}{l}\text { What is the level of knowledge in the application of standards } \\
\text { and / or standards in energy efficiency management systems } \\
\text { in the institutions involved? }\end{array}$ &, 138 & ,776 &, 040 &, 141 &, 120 &,- 125 \\
\hline $\begin{array}{l}\text { What is the quality of the energy efficiency management } \\
\text { services provided by the departments or areas dedicated to } \\
\text { their execution in the institutions involved? }\end{array}$ &, 035 & ,769 & , 109 &, 090 &, 257 &,- 027 \\
\hline $\begin{array}{l}\text { In what percentage does the Organization where you work use } \\
\text { renewable energy sources? }\end{array}$ &, 142 &, 504 & ,362 &, 082 &,- 195 &, 158 \\
\hline $\begin{array}{l}\text { What percentage of knowledge do you have? In energy effi- } \\
\text { ciency related to lighting? }\end{array}$ &, 454 & ,477 &,- 023 &,- 006 &, 127 &,- 013 \\
\hline Are lighting devices with sensors used in your work or home? & 096 &, 154 &, 788 & ,007 &,- 024 & ,081 \\
\hline $\begin{array}{l}\text { At your work or home, are image recognition sensors used by } \\
\text { people for energy efficiency with luminaires? }\end{array}$ &,- 085 &, 190 &, 766 &, 057 &, 012 &,- 097 \\
\hline $\begin{array}{l}\text { The ISO } 50001 \text { standard for energy management is applied at } \\
\text { your workplace }\end{array}$ &, 191 &, 385 &, 431 &, 035 &,- 074 &, 347 \\
\hline $\begin{array}{l}\text { Do you consider using lighting devices with energy-saving } \\
\text { mode? }\end{array}$ &, 050 &, 074 &,- 107 &, 856 &, 024 & , 109 \\
\hline $\begin{array}{l}\text { Have you considered in your home or institution acquire } \\
\text { sensors to optimize the consumption of electricity? }\end{array}$ & ,098 & ,136 &, 069 &, 832 &, 071 &,- 039 \\
\hline $\begin{array}{l}\text { Do you understand the operation of the sensors in video } \\
\text { cameras? }\end{array}$ &, 363 &, 140 &, 245 &, 587 &, 158 &,- 113 \\
\hline $\begin{array}{l}\text { Do you consider important the cost generated by the luminar- } \\
\text { ies in your place of work or home? }\end{array}$ &, 189 &, 030 &, 115 & ,096 &, 698 & , 105 \\
\hline $\begin{array}{l}\text { In what percentage does the Organization where you work use } \\
\text { traditional energy sources? }\end{array}$ &, 111 & ,231 &,- 267 &,- 007 &, 673 &,- 014 \\
\hline $\begin{array}{l}\text { At what percentage would you express the cost benefit when } \\
\text { using recognition sensors for energy efficiency with lumi- } \\
\text { naires? }\end{array}$ &, 192 &, 385 &,- 283 & ,099 &, 470 &,- 122 \\
\hline $\begin{array}{l}\text { In your work or home do you know the environmental impact } \\
\text { of the use of renewable energy sources? }\end{array}$ & ,409 &, 067 & ,239 &, 141 &, 432 &, 062 \\
\hline $\begin{array}{l}\text { In your place of work or home, the lights are used for long } \\
\text { periods of time? }\end{array}$ &, 055 &,- 004 &, 126 &, 094 & ,189 &, 820 \\
\hline Turn off lights at work or home when they are not used? &, 063 &,- 010 & 245 & 278 &, 312 &,- 457 \\
\hline
\end{tabular}


In Table 4. It is again shown that there is a correlation between the variables with a value of 0.829 as a result of Kaiser-Meyer-Olkin.

Table 4. Second KMO result and Bartlett test

\begin{tabular}{|l|l|c|}
\hline Sampling adaptation measure of Kaiser-Meyer-Olkin. &, 829 \\
\hline \multirow{3}{*}{ Bartlett's sphericity test } & Approximate Chi-square & 1598,128 \\
\cline { 2 - 3 } & Gl & 120 \\
\cline { 2 - 3 } & Sig. &, 000 \\
\hline
\end{tabular}

Table 5. Matrix of rotated factors

\begin{tabular}{|c|c|c|c|c|c|}
\hline \multirow{2}{*}{ Reagents } & \multicolumn{5}{|c|}{ Factor } \\
\hline & 1 & 2 & 3 & 4 & 5 \\
\hline Do you know the types of sensors used in lighting? &, 837 & ,049 & 074 &, 080 &,- 103 \\
\hline Do you know about the latest technological advances in energy efficiency? &, 790 &, 135 &,- 032 &, 043 &, 105 \\
\hline Know the benefits of renewable energy? & ,785 & 069 &,- 028 &,- 196 & ,197 \\
\hline Do you know about sensors? & ,779 &, 030 & 061 & ,046 &,- 023 \\
\hline Do you know about light devices connected to a wireless network? & ,702 & , 168 & 171 & ,166 &,- 133 \\
\hline Do you have knowledge about energy efficiency? & ,694 &, 108 &, 070 &, 006 &, 210 \\
\hline Do you have knowledge about traditional energies? & ,685 & 096 & 079 &,- 079 &, 162 \\
\hline $\begin{array}{l}\text { What is the quality of the energy efficiency management services provided } \\
\text { by the departments or areas dedicated to their execution in the institutions } \\
\text { involved? }\end{array}$ & ,078 & ,775 & ,096 &, 080 & ,090 \\
\hline $\begin{array}{l}\text { What are the levels of application based on the recognition of people for } \\
\text { the management of energy efficiency in involved institutions? }\end{array}$ &, 144 & ,766 &,- 009 &, 137 &, 059 \\
\hline $\begin{array}{l}\text { To what extent is technological management applied to energy efficiency } \\
\text { in involved institutions? }\end{array}$ &, 045 & ,765 & ,076 &, 125 &, 057 \\
\hline $\begin{array}{l}\text { What is the level of knowledge in the application of standards and / or } \\
\text { standards in energy efficiency management systems in the institutions } \\
\text { involved? }\end{array}$ &, 157 & ,720 & ,093 & 063 &,- 022 \\
\hline Do you consider using lighting devices with energy-saving mode? &, 046 & 059 & ,949 &,- 084 & ,292 \\
\hline $\begin{array}{l}\text { Have you considered in your home or institution acquire sensors to opti- } \\
\text { mize the consumption of electricity? }\end{array}$ & ,136 & , 142 &, 637 &, 127 &,- 115 \\
\hline Are lighting devices with sensors used in your work or home? &, 083 & ,093 &,- 014 &, 880 & ,266 \\
\hline $\begin{array}{l}\text { At your work or home, are image recognition sensors used by people for } \\
\text { energy efficiency with luminaires? }\end{array}$ &,- 069 & ,219 & ,061 &, 547 &,- 042 \\
\hline $\begin{array}{l}\text { In your place of work or home, the lights are used for long periods of } \\
\text { time? }\end{array}$ & ,082 & ,058 &, 041 & 093 & ,187 \\
\hline
\end{tabular}

In this second phase, the sedimentation graph is considered, which allows determining how many factors must be maintained. Normally, the graph shows the clear break between the steep slope of the most important factors and the gradual descent of the rest. Another method that allows to determine how many factors should be conserved is the Kaiser criterion, which consists of preserving the factors, where their associated eigenvalue is greater than 1, according to the author [19].

In the first phase, 6 factors obtained through the rotated matrix were shown, after having extracted the ten variables that did not comply with the proposed range, the number of factors in this stage was reduced, reaching 5 factors that are retained and shown a greater correlation with respect to the rest. 
In the matrix of rotated factors, the correlations between the variables are shown and, according to this, they were analyzed again and it was found that 5 of them are not within the specified range that is $\geq 0.5$, so that an additional procedure is performed again, excluding the 5 extracted variables, and in this way a correlation value close to one is obtained.

In Table 5 of the matrix of rotated factors, the questions that were extracted and highlighted in bold and underlined are shown.

Before finishing this second phase, it is observed in Table 6 , that in the transformation matrix of the factors there is still a close correlation between each of the factors, thus improving the variability, in relation to the same matrix of the first phase.

Table 6. Factor transformation matrix

\begin{tabular}{|c|c|c|c|c|c|}
\hline Factor & $\mathbf{1}$ & $\mathbf{2}$ & $\mathbf{3}$ & $\mathbf{4}$ & $\mathbf{5}$ \\
\hline 1 &, 048 &, 060 &, 950 &,- 084 &, 292 \\
\hline 2 &, 892 &, 361 &,- 068 &, 253 &, 072 \\
\hline 3 &,- 414 &, 449 &, 012 &, 775 &, 162 \\
\hline 4 &,- 170 &, 815 &,- 040 &,- 528 &,- 162 \\
\hline 5 &, 042 &,- 018 &, 303 &, 221 &,- 926 \\
\hline
\end{tabular}

\subsection{Results and analysis of the third phase}

On the basis of the analysis of the second phase, which does not consider five variables, we proceeded to the third procedure, in which a lower correlation was established and the maximum likelihood is considered as analysis. The remaining reagents that are not within the correlation range are also discarded and the sedimentation graph option is activated to determine how many factors are retained after the second phase.

In Table 7. Again it is shown that there is a correlation between the variables (0.819) as KMO results. In the second phase, five factors obtained through the rotated matrix showed, after unscrewing the five variables that did not meet the proposed range, the number of factors in this stage was reduced, obtaining three factors are retained and that show a greater correlation with respect to the rest.

In the matrix of rotated factors, the correlations between each of the variables are shown and, therefore, they are re-analyzed and it was found that two of these variables are not within the specified range that is $\geq 0.5$, so that performed an additional procedure, excluding the 2 variables, and thus obtain a correlation value close to one.

Table 7. Third KMO result and Bartlett test

\begin{tabular}{|l|l|c|}
\hline Sampling adaptation measure of Kaiser-Meyer-Olkin. &, 819 \\
\hline \multirow{3}{*}{ Bartlett's sphericity test } & Approximate Chi-square & 1086,354 \\
\cline { 2 - 3 } & gl & 55 \\
\cline { 2 - 3 } & Sig. &, 000 \\
\hline
\end{tabular}

In Table 8, the questions that were extracted are shown, which are highlighted in bold and underlined. 
Table 8. Matrix of rotated factors

\begin{tabular}{|l|c|c|c|}
\hline \multicolumn{1}{|c|}{ Reagents } & \multicolumn{2}{c|}{ Factor } \\
\cline { 2 - 4 } & $\mathbf{1}$ & $\mathbf{2}$ & $\mathbf{3}$ \\
\hline Do you know the types of sensors used in lighting? &, 840 &, 062 &, 179 \\
\hline Know the benefits of renewable energy? &, 821 &, 137 &,- 553 \\
\hline Do you know about the latest technological advances in energy efficiency? &, 776 &, 171 &,- 010 \\
\hline Do you know about sensors? &, 771 &, 066 &, 000 \\
\hline Do you know about light devices connected to a wireless network? &, 715 &, 191 &, 214 \\
\hline $\begin{array}{l}\text { What is the quality of the energy efficiency management services provided by the } \\
\text { departments or areas dedicated to their execution in the institutions involved? }\end{array}$ &, 065 &, 794 &, 030 \\
\hline $\begin{array}{l}\text { To what extent is technological management applied to energy efficiency in in- } \\
\text { volved institutions? }\end{array}$ &, 026 &, 776 &, 153 \\
\hline $\begin{array}{l}\text { What are the levels of application based on the recognition of people for the man- } \\
\text { agement of energy efficiency in involved institutions? }\end{array}$ &, 115 &, 771 &, 085 \\
\hline $\begin{array}{l}\text { What is the level of knowledge in the application of standards and / or standards in } \\
\text { energy efficiency management systems in the institutions involved? }\end{array}$ &, 120 &, 715 &, 090 \\
\hline $\begin{array}{l}\text { Do you consider using lighting devices with energy-saving mode? } \\
\text { Are lighting devices with sensors used in your work or home? }\end{array}$ &, 087 &, 141 &, 006 \\
\hline
\end{tabular}

Table 9. Matrix factor transformation

\begin{tabular}{|c|c|c|c|}
\hline Factor & $\mathbf{1}$ & $\mathbf{2}$ & $\mathbf{3}$ \\
\hline 1 &, 824 &, 138 &,- 550 \\
\hline 2 &, 099 &, 920 &, 380 \\
\hline 3 &, 558 &,- 367 &, 744 \\
\hline
\end{tabular}

Before finishing this third phase, it is observed in Table 9, that in the transformation matrix of the factors there is still a close correlation between each of the factors, thus improving the variability, in relation to the same matrix of the second phase.

\subsection{Results and analysis of the fourth phase}

After having extracted 17 reagents in the three previous phases, a fourth phase was carried out, in which it was shown that the remaining 9 variables correlated with each other, which shows that the reduction analysis of dimensions reached this instance, so that no other variable can be eliminated, since all have a correlation coefficient $\geq 0.5$, which indicates that all have a strong correlation between them.

The sedimentation graph, see figure 1, is considered to determine how many factors are retained in this third phase. In phase one, 6 factors were shown in the rotated matrix; after having extracted the ten variables that did not meet the proposed range, the number of factors in phase two was reduced. 


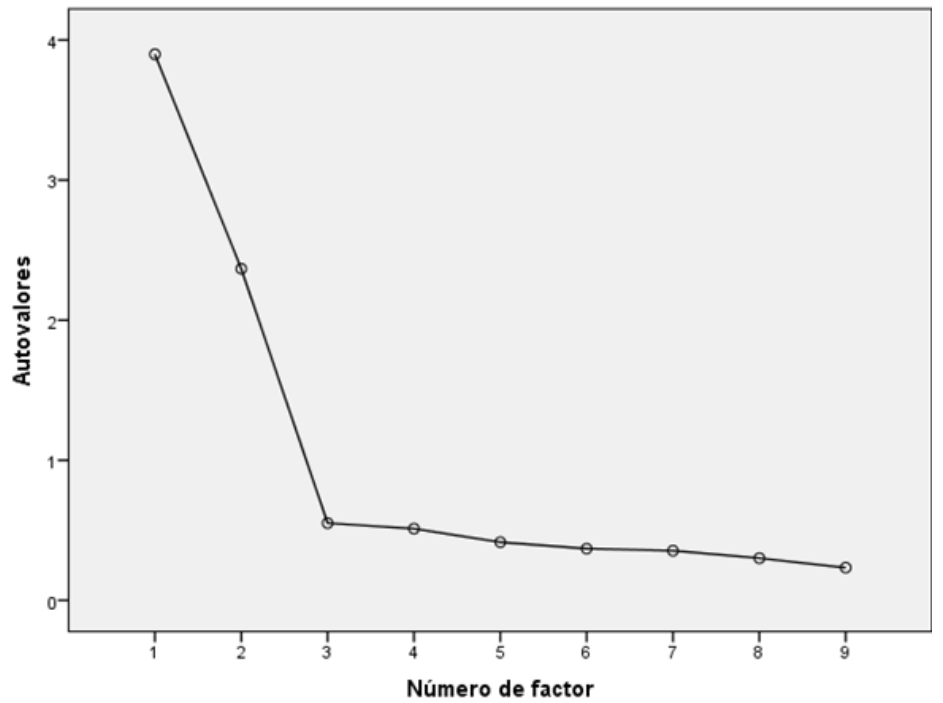

Fig. 1. Sedimentation graph

Five factors that are conserved after having suppressed the other 5 reagents that did not meet the proposed correlation rank are taken as reference. In the third phase, 2 reagents that did not meet the required range were eliminated and in the fourth phase, although no variable with a lower coefficient than that established was presented, the number of factors was reduced, which resulted in as a result 2 of them have a close correlation with each other.

\section{Table 10.}

Matrix of rotated components

\begin{tabular}{|l|c|c|}
\hline \multicolumn{1}{|c|}{ Reagents } & \multicolumn{2}{c|}{ Factor } \\
\cline { 2 - 3 } & $\mathbf{1}$ & $\mathbf{2}$ \\
\hline Do you know the types of sensors used in lighting? &, 832 &, 068 \\
\hline Do you know about the latest technological advances in energy efficiency? &, 791 &, 149 \\
\hline Do you know about sensors? &, 783 &, 045 \\
\hline Know the benefits of renewable energy? &, 765 &, 060 \\
\hline Do you know about light devices connected to a wireless network? &, 709 &, 198 \\
\hline $\begin{array}{l}\text { To what extent is technological management applied to energy efficiency in in- } \\
\text { volved institutions? }\end{array}$ &, 044 &, 787 \\
\hline $\begin{array}{l}\text { What is the quality of the energy efficiency management services provided by the } \\
\text { departments or areas dedicated to their execution in the institutions involved? }\end{array}$ &, 081 &, 786 \\
\hline $\begin{array}{l}\text { What are the levels of application based on the recognition of people for the man- } \\
\text { agement of energy efficiency in involved institutions? }\end{array}$ &, 129 &, 776 \\
\hline $\begin{array}{l}\text { What is the level of knowledge in the application of standards and / or standards in } \\
\text { energy efficiency management systems in the institutions involved? }\end{array}$ &, 144 &, 719 \\
\hline
\end{tabular}

After having obtained the sedimentation graph, it can be observed in the matrix of rotated factors that between the variables that were not eliminated and the factors obtained in the graph there is a high correlation between them, showing in Table 10 
that it is no longer necessary perform another analysis, considering all the variables are in the established correlation range.

Then, based on the transformation matrix of the factors, a comparison is made between the matrix of the first phase where the factor with the highest variability $(0.869)$ is observed, considering that the fourth and last phase shows us the two factors that they remained have the same variability $(0.870)$, which indicates that all the factors are related among them. See Table 11 .

Table 11. Factor transformation matrix

\begin{tabular}{|c|c|c|}
\hline Factor & $\mathbf{1}$ & $\mathbf{2}$ \\
\hline 1 &, 870 &, 493 \\
\hline 2 &,- 493 &, 870 \\
\hline
\end{tabular}

Finally, in relation to the analysis performed on the results obtained in the four phases, we obtained 9 variables out of the 26 admitted at the beginning, eliminating 17 that did not comply with the ranges considered.

\subsection{Alpha result of cronbach}

As a result of the reliability analysis, we obtained (0.880), in the Cronbach alpha coefficient in relation to the 26 items, that according to the authors' criteria [16], [20], the coefficient is good and very favorable that allowed the development of the factorial analysis.

\section{Conclusion}

The exploratory factor analysis performed on the data obtained through the field study, allowed to know that the institutions involved in this study do not have intelligent systems in terms of lighting, and that, due to lack of budget or lack of knowledge of the standards and / or related to the management of energy in these organizations do not apply to the word efficiency, because all systems that are installed in organizations are conventional, old and do not have devices that can turn them on automatically.

Apply the KMO test and Bartlett's sphericity as a technique, considering the correlation range $\geq 0.5$ between the reagents as reference; was feasible, through the analysis of the main components, it was obtained that the correlations between the input variables are different from zero, that is to say that there is a correlation between them $(0.832)$ and that the analysis of the results is reliable.

This process allowed to show the correlation between the reactants entered in each phase, which shows that the analysis is feasible, since it was obtained as the last result in the factor transformation matrix $(0.870)$ that the correlation was within the range established, which shows that the work is viable considering the three dimensions established in knowledge, application and management. 
The alpha analysis of cronbach $(0.880)$ certified the reliability applied by this instrument and allowed the factor analysis developed to be based. Therefore, it is concluded that the acquisition of devices associated with energy efficiency and applied to lighting systems is feasible to improve electricity consumption, which allows generating savings in the places where they are implemented considering the environment of a smart grid.

\section{Acknowledgement}

Acknowledge the help to Dr. Antonio J. Carpio Camargo, researcher at the University of Córdoba - Spain, for his constructive comments and suggestions.

\section{References}

[1] G. Belcredi, P. Modernell, N. Sosa, L. Steinfeld, and F. Silveira, "An implementation of a home energy management platform for Smart Grid," Innov. Smart Grid Technol. Lat. Am. (ISGT LATAM), 2015 IEEE PES, pp. 270-274, 2015. https://doi.org/10.1109/isgt-la.2015. $\underline{7381166}$

[2] J. L. Hurink, A. Molderink, G. J. M. Smit, V. Bakker, and M. G. C. Bosman, "Planning the production of a fleet of domestic combined heat and power generators," Eur. J. Oper. Res., vol. 216, no. 1, pp. 140-151, 2011. https://doi.org/10.1016/j.ejor.2011.07.033

[3] B. Asare-Bediako, P. F. Ribeiro, and W. L. Kling, "Integrated energy optimization with smart home energy management systems," 2012 3rd IEEE PES Innov. Smart Grid Technol. Eur. (ISGT Eur., pp. 1-8, 2012. https://doi.org/10.1109/isgteurope.2012.6465696

[4] T. Kaur and I. Chana, "Energy Efficiency Techniques in Cloud Computing: A Survey and Taxonomy," ACM Comput. Surv., vol. 48, no. 2, pp. 1-46, 2015. https://doi.org/10.1145/ $\underline{2742488}$

[5] S. J. Alcolea, "Eficiencia Energética en iluminación," 2011.

[6] A. Contreras, "Diseño de un sistema de automatización para el sistema de iluminación de una planta industrial," 2011. https://doi.org/10.24133/maskay.v2i1.143

[7] P. J. Ferrando and C. Carrasco Anguiano, "El Analisis Factorial Como Tecnica De Investigacion Psicologica," Red Rev. Cient. Am. Lat., vol. 31, no. 1, pp. 18-33, 2010.

[8] S. M. A. Méndez, Martinez Carolina; Roldón, "Metodología. ANÁLISIS FACTORIAL," 2012.

[9] Fernandez Santiago, “Análisis De Componentes Principales (Acp),” Análisis Componentes Princ., pp. 1-30, 2011. https://doi.org/10.21134/haaj.v17i2.332.s34

[10] J. Echeverría, "Apropiación social de las tecnologías de la información y la comunicación," Qurriculim, vol. 4, pp. 91-115, 2002. https://doi.org/10.2307/j.ctv8xnjck.10

[11] J. J. Mazón Ramírez, J. Martínez Stack, and A. Martínez González, "La evaluación de la función docente mediante la opinión del estudiante. un nuevo instrumento para nuevas dimensiones: COED,” Rev. la Educ. Super., vol. XXXVIII, no. 1, pp. 113-139, 2009. https://doi.org/10.4995/thesis/10251/1891

[12] R. Serrano Rodríguez, M. I. Amor Almedina, Á. Guzman Cedeño, and J. Guerrero-Casado, "Validation of an Instrument to Evaluate the Development of University Teaching Competences in Ecuador," J. Hispanic High. Educ., 2018. https://doi.org/10.1177/15381927187 $\underline{65076}$ 
[13] A. Fernández Aráuz, "Aplicación del análisis factorial confirmatorio a un modelo de medición del rendimiento académico en lectura," Rev. Ciencias Económicas, vol. 33, no. 2, p. 39, 2015. https://doi.org/10.15517/rce.v33i2.22216

[14] R. W. Stratton, "Implications of PL 93-641 for Catholic hospitals," vol. 30, pp. 11511169, 1975.

[15] H. A. Hernàndez and A. E. Pascual Barrera, "Validación de un instrumento de investigacion para el diseño de una metodología de autoevaluación del sistema de gestión ambiental.," Rev. Investig. Agrar. y Ambient., vol. 9, no. 1, pp. 157-164, 2018. https://doi.org/ $\underline{10.22490 / 21456453.2186}$

[16] George and Mallery, IBM SPSS Statistics 23 Step by Step a simple guide and reference. 2016. https://doi.org/10.4324/9781315545899

[17] Y. Yang and S. B. Green, "Coefficient alpha: A reliability coefficient for the 21 st century?” J. Psychoeduc. Assess., vol. 29, no. 4, pp. 377-392, 2011.

[18] W. Garcia, "CURSO DE EXPERTO: 'METODOLOGÍA DE LA INVESTIGACIÓN,", CURSO Expert. "Metodol. LA Investig. ," vol. 1, p. 23, 2017.

[19] Y. Ruiz, "Aplicación del análisis de componentes principales como técnica para obtener índices sintéticos de calidad ambiental," Scientia, vol. 4, no. 2, pp. 145-153, 2012.

[20] R. R. G. Joseph A. Gliem, "Calculating, Interpreting, and Reporting Cronbach's Alpha Reliability Coefficient for Likert-Type Scales," in Midwest Research-to-Practice Conference in Adult Continuing an Community Education, 2003, pp. 82-88.

\section{Authors}

Washington Garcia Quilachamin. Received the degree of magister in Informatics Management and New Technology in University Technical Federico Santa Maria of Chile (2008), Campus Guayaquil, Ecuador. He is currently pursuing the Ph.D. in System engineering degree with the National University of San Marcos, Lima, Peru, under the supervision of Dra. Luzmila Pro Concepción. He is currently a full time Professor of computer science in the Faculty of Electric Engineering at the Laica Eloy Alfaro de Manabí University, Ecuador. member of ISOC-Cap.Ec. His research activity is related to the Internet of Things, Cloud Computing, intelligence systems, image processing, pattern recognition, particularly oriented to an intelligent network and Smart grid.

Luzmila Elisa Pro Concepcion. Professor in the Main Category of the Academic Department of Computer Science of the School of Systems and Information Engineering of the National University of San Marcos Lima, Peru, with a PhD in Systems Engineering in Federico Villarreal University Lima Peru (2010), Master in Computing and Computer Science Faculty of Mathematical Sciences of the National University of San Marcos, Lima, Peru, (1998). She was dean of the Faculty of Systems and Information Engineering of the National University of San Marcos in 2006 and 2016. Director of the Research Institute of the Faculty of Systems and Information Engineering between 2011 and 2015, Director of the Unit of Postgraduate the Faculty of Systems and Information Engineering in 2015. Currently a Coordinator of the Doctorate Courses in the Graduate Unit of the Faculty of Systems and Information Engineering. Currently responsible for the research group "Information Technology with Applications in the Biomedical Sciences BIOMEDICAL-IT", of the UNMSM. She has 
been responsible for research projects such as genetic algorithms, Big data, image processing and recognition, intelligent systems, home automation, ontological engineering. She is a thesis advisor for Internet projects on video games, cloud computing, intelligent systems, among others. She has also made publications and presentation for research events.

Evelyn Santana Mantuano. Is currently a student assistant researcher in the Faculty of Electric Engineering at Laica Eloy Alfaro of Manabi University, Manta, Ecuador. Her research activity is related to automation control systems, project management, statistics and particularly oriented to intelligent network.

Richard José Salazar. He was born in Cabimas in 1967. He received his degree in Electrical Engineering from the Santiago Mariño Polytechnic University Institute in 2000. He holds a master's degree in engineering science in Maintenance Management from the University of Zulia, Venezuela. Doctorate studies at the Rafael Maria Baralt Experimental University of Venezuela, in Education Sciences, and in the field of research is related to University Education in Automatic Control Systems. He is currently a full time Professor of engineering science in the Faculty of Electric Engineering at the Laica Eloy Alfaro de Manabí University, Ecuador.

Article submitted 2019-06-09. Resubmitted 2019-07-03. Final acceptance 2019-07-03. Final version published as submitted by the authors 